\title{
Work hard, play hard-especially with the little ones
}

\author{
Ryan A. Macke, MD
}

From the Department of Surgery, University of Wisconsin School of Medicine and Public Health, Madison, Wis. Disclosures: Author has nothing to disclose with regard to commercial support.

Received for publication April 1, 2016; accepted for publication April 1, 2016; available ahead of print April 30, 2016.

Address for reprints: Ryan A. Macke, MD, H4/318 Clinical Sciences Center, 600 Highland Ave, Madison, WI 53792 (E-mail: macke@surgery.wisc.edu).

J Thorac Cardiovasc Surg 2016;152:360-1

$0022-5223 / \$ 36.00$

Copyright (C) 2016 by The American Association for Thoracic Surgery

http://dx.doi.org/10.1016/j.jtcvs.2016.04.019

In this issue of The Journal, Bakhos and Castillo-Sang ${ }^{1}$ focus on an often underappreciated, but supremely important aspect of our lives as cardiothoracic surgeons, work-life balance. This thoughtful editorial is directed primarily at young surgeons early in practice; however, achieving optimal work-life balance is likely something that even our most senior colleagues have grappled with throughout their careers. Many of the points made are also relevant for surgeons in training. Although these recommendations are noted to be from "a man's perspective" (after all, both authors are male!), I would argue that the salient points addressed in this article are applicable to all surgeons, regardless of gender, stage of career, or type of practice.

Bakhos and Castillo-Sang ${ }^{1}$ reference some eye-opening data, specifically the 2008 American College of Surgeons survey results reporting that $40 \%$ of surgeons in general met criteria for "burnout" and that $30 \%$ had a mental quality of life well below the population norm. ${ }^{2}$ Another previous study reported that among 14 surgical specialties, cardiothoracic surgeons spent the most time in the operating room and experienced the second-highest rate of suicidal ideation. ${ }^{3}$ Clearly this is an issue that requires our attention as a specialty.

On the surface, the outline for success appears relatively straightforward: set goals, get organized, and make time for the important things. The recipe for achieving a fulfilling and balanced life in cardiothoracic surgery is a complex one, however, as demonstrated in the authors' Venn diagram depicting the necessary intersection of various non-work-related and work-related factors. Both personal and career goals must be determined with honest introspection and revised regularly, because life is dynamic and most of our careers will evolve considerably with time. To achieve these goals, a support system must be constructed that includes one's spouse, family, friends, and colleagues. Achieving work-life balance is not a challenge that can be conquered alone. Communication on all fronts is therefore absolutely necessary. Bakhos and Castillo-Sang ${ }^{1}$ also highlight the importance of taking care of ourselves-something many surgeons tend to neglect. Time must be made to ensure our own physical,

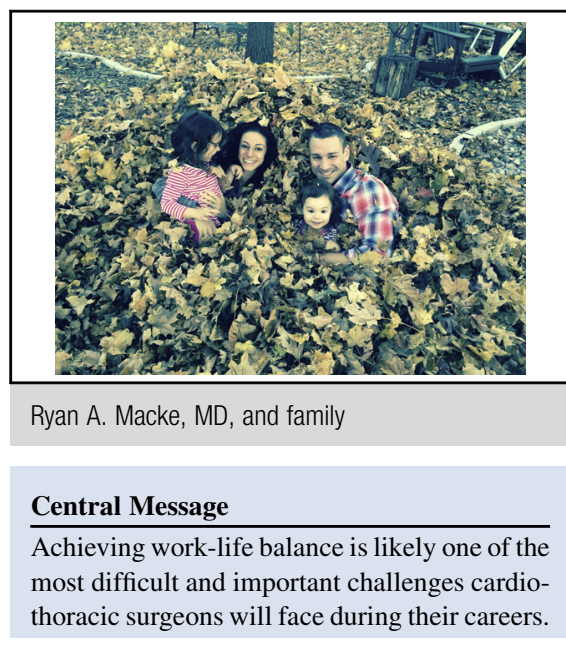

See Editorial Commentary page 357.

mental, and financial health if we are to be at our best for both our patients and our families.

One concept that is briefly touched on in this thoughtful editorial deserves special mention: being present. Our lives as surgeons are often chaotic, and we are frequently pulled in multiple directions simultaneously. Separating our minds from work-related issues after finally making it home can be difficult. We may find ourselves obsessing over some postoperative complication, mentally preparing for an upcoming challenging case, or panicking about a rapidly approaching deadline. At times, these thoughts can be consuming and can result in others around us perceiving us as disconnected or distant. Personally, I have found this to be one of the most difficult challenges I had to overcome early in my career. Once I became aware this phenomenon and began to make a more conscious effort to be more present - not just physically but mentally as well-I discovered that I was able to enjoy my job and my family even more, and with a greater sense of balance.

The editorial by Bakhos and Castillo-Sang ${ }^{1}$ provides a number of recommendations to help avoid burnout and achieve work-life balance. Readers are encouraged to consider these suggestions thoughtfully and apply them to their own lives, particularly when the weight of "the job" starts to result in an increasingly unbalanced or frustrating existence. The attitude of "work hard, play hard" seems most appropriate when considering what cardiothoracic surgeons must do to be content and successful from a career and personal standpoint. Working hard at the hospital may lead to success in one's career, but making time to play hard, especially with the little ones, and placing an 
emphasis on being present is critical if a harmonious work-life balance is to be achieved.

\section{References}

1. Bakhos CT, Castillo-Sang M. How to balance family with career: a man's perspective. J Thorac Cardiovasc Surg. 2016;152:357-9.
2. Shanafelt TD, Balch CM, Bechamps G, Russell T, Dyrbye L, Satele D, et al Burnout and career satisfaction among American surgeons. Ann Surg. 2009;250: 463-71.

3. Balch CM, Shanafelt TD, Sloan JA, Satele DV, Freischlag JA Distress and career satisfaction among 14 surgical specialties, comparing academic and private practice settings. Ann Surg. 2011;254: 558-68. 